\title{
Model for the Integration of Distributed Energy Resources in Energy Markets by an Aggregator
}

\author{
João Spínola, Pedro Faria, Zita Vale \\ GECAD - Research Group on Intelligent Engineering and Computing for Advanced Innovation and Development, \\ Institute of Engineering - Polytechnic of Porto (ISEP/IPP) \\ Rua Dr. António Bernardino de Almeida, 431, 4200-072 Porto, Portugal \\ jafps@isep.ipp.pt, pnfar@isep.ipp.pt, zav@isep.ipp.pt
}

\begin{abstract}
The increase of distributed energy resources in energy systems and current legislation concerning the participation in energy markets, is causing a high wasted potential of energy supply and flexibility services. In this paper, it is proposed a methodology for the management and integration of distributed energy resources in energy systems and markets, through the application of an aggregator. Also, the aggregator provides demand response programs based on tariffs, thus enabling different types of participations. Aggregation is performed using K-Means clustering algorithm, and serves as basis for remuneration, where the aggregated energy and cost of resources is obtained. Given this methodology, the aggregator obtains the energy available and the minimum sell cost to negotiate in market, with the intent of obtaining profit in its operation. The methodology is validated through a case study, with 20 consumers and 25 distributed generators.
\end{abstract}

Index Terms-Aggregator, Clustering, Demand response, Distributed generation, Energy markets.

\section{INTRODUCTION}

The introduction of distributed energy resources in energy markets is a subject of great relevance in today's energy systems, since the major issue is their operation capacity [1]. In this way, aggregators and virtual power plants can provide a reliable solution. The distributed energy resources, when managed by an aggregator, are represented as a unique resource with characteristics that reflect the aggregated resources [2], [3].

An aggregator managing a given number of resources or region, implies a simplification of processes to the operators, since the number of resources to be considered is reduced and energy negotiation and trade can be made [4]. Also, if balance responsible parties (BRPs) exist, the activities developed by the aggregator can also provide useful services to the BRPs [5]. In fact, several countries of the European Union (EU) have introduced and accepted the concept of aggregators operating in their energy systems providing service mainly through consumers [6]. For example, according to [7], in France aggregated loads (aggregator) are accepted in every ancillary service's program. Also, aggregator and BRP relations are accounted for and are rearranged based on two

This work has received funding from the following projects: NETEFFICITY Project (ANI | P2020 - 18015); and from FEDER Funds through COMPETE program and from National Funds through FCT under the project UID/EEA/00760/2013. ways: the aggregator does not deal directly with the BRP, instead with either establishes a contract with a supplier to provide flexibility services; or performs market negotiations and then compensation fees must be made by the aggregator to the BRP, as illustrated in Figure 1.

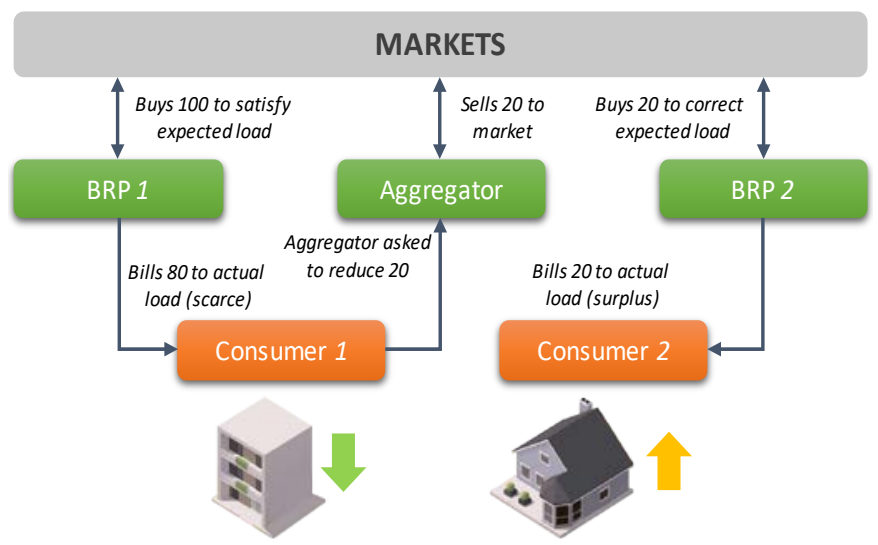

Figure 1. Integration of the aggregator with the BRP (adapted from [8]).

The usefulness of an aggregator is specially seen as a flexibility provider, through the gathering of active consumers that can participate in the aggregator's demand response programs [9]. Demand Response (DR) is defined by FERC (Federal Energy Regulatory Commission) as "changes in electric use by demand-side resources from their normal consumption patterns in response to changes in the price of electricity, or to incentive payments designed to induce lower electricity use at times of high wholesale market prices or when system reliability is jeopardized”, in [10]. In this way, aggregators can manage several demand-side resources and obtain flexibility from these, that can be negotiated in the energy markets auction, through bilateral contracts, trade. Regarding production-side resources, the aggregator assumes the role of a virtual power plant, as referred before [11], [12]. These resources often belong to consumers (prosumers) and thus have small capacity, therefore there is the need for an entity capable of aggregating these resources and negotiate them in the energy markets. The flexibility resources with small reduction capacity (e.g. residential), makes harder the consideration of these resources by the system operators. 


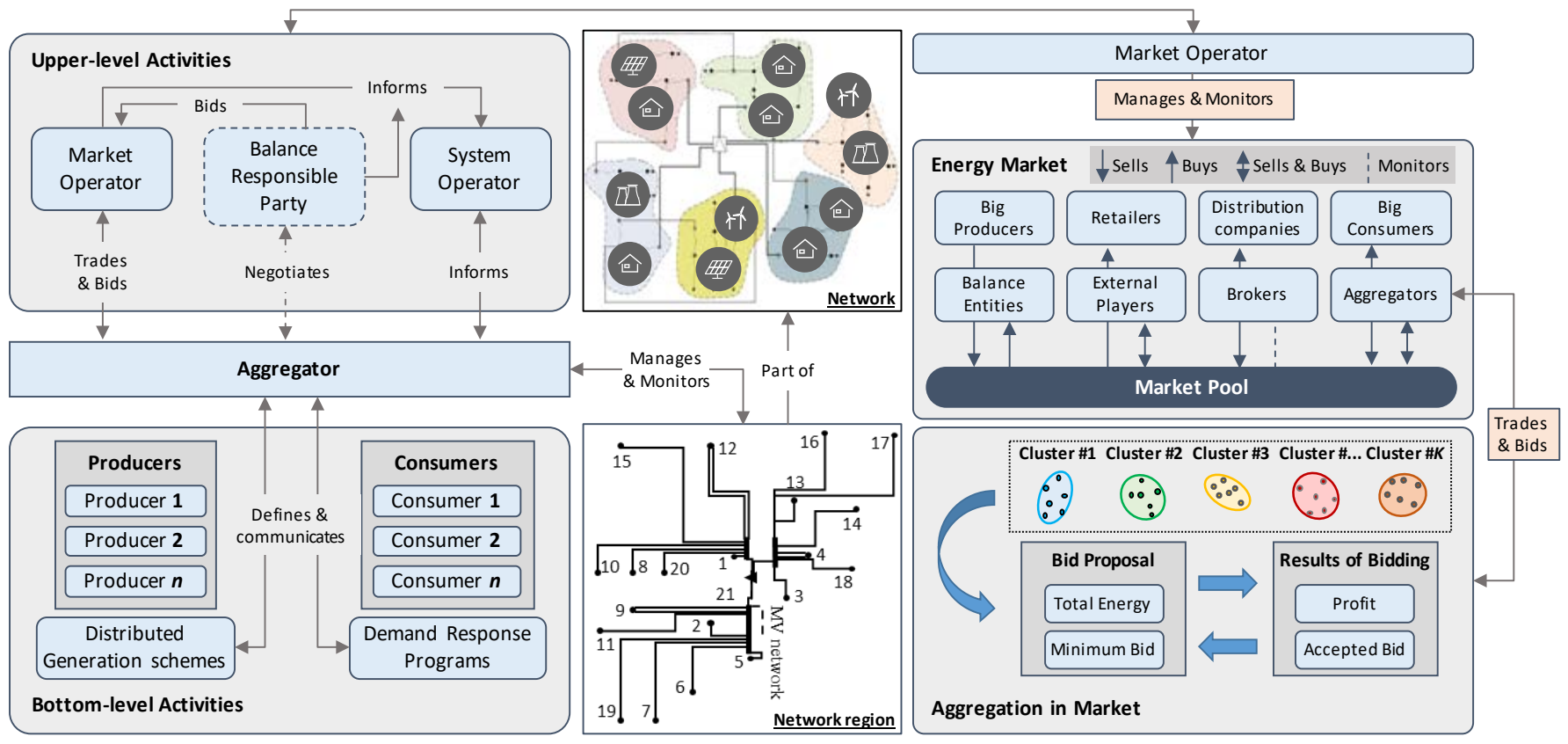

Figure 2. Scheme of the proposed methodology.

In the present paper, it is proposed a methodology to support the aggregator in its activities, with focus on the participation of aggregated distributed energy resources in energy markets, and on how the aggregator can benefit from this participation while promoting their inclusion.

After this introductory section, section II presents the proposed methodology for the aggregator activities, section III shows the mathematical formulation considered, section IV the case study used to implement the methodology, section $\mathrm{V}$ the results, and finally section VI, the work conclusions.

\section{Proposed Methodology}

In this section, it is explained the proposed methodology and all its components, regarding the scheduling, aggregation, and remuneration activities performed by the aggregator. The proposed methodology is shown in Figure 2. At the end of the methodology, the output results are the energy and cost of each group of resources made, according to the specifications of the aggregator. With this information, the aggregator can negotiate in market by bidding the available energy amount at a given price, however, the sell price of this bid must be equal or higher to the cost of each group for the aggregator to obtain profit or at least regain what was spent on the distributed resources. The activities of the aggregator are divided in two types: upper-level and bottom-level activities, as explained in [13].

The scheduling of resources considers external suppliers and two types of distributed energy resources, namely, distributed generators and active consumers. For the production-side resources, the methodology considers a linear cost function for both distributed generators and external suppliers. Regarding active consumers, it is considered that these can be enrolled in three different types of demand response, namely, load reduction, curtailment, and load shifting. In this way, only the reduction and curtailment energy amounts obtained are considered by the aggregator to be scheduled and therefore negotiated in the energy market. The load shifting model is based on [14]. In the case of the demand-side resources, the cost considered is also linear for reduction and curtailment, while load shifting is free.

Aggregation of resources is made using K-Means clustering algorithm, considering the observations of the energy scheduled and the discriminated cost of that scheduling. It is important to notice that the aggregation is only made considering the resources with participation in the scheduling, i.e. if the resource is not affected by the scheduling of the aggregator, then it is also not considered in the aggregation process.

The remuneration of resources is computed after the aggregation, since the groups need to be made to define a group tariff, i.e. the resources belonging to a given group are remunerated at the same price. In this case, it is considered that the maximum price in the group, which corresponds to the group tariff, therefore paying the most expensive consumers a fair amount, and the least expensive an incentive to participation since the payment is superior to their initial expected price. This insures that most of the consumers is encouraged to participate in the aggregator's schedule.

In sum, each of the groups formed will represent a bid made by the aggregator in the energy market (seen as a bid group), considering the energy obtained from the resources within that group, and the respective group tariff as the minimal acceptance rate for the aggregator. The energy in each group corresponds to the sum of the scheduling obtained for the distributed resources in that same group. This type of analysis facilitates the activities developed by the aggregator, namely, by providing a simple decision strategy based on the financial balance computation of its participation in market. 


\section{MATHEMATICAL FORMULATION}

In this section, it is presented the mathematical formulation that composes the proposed methodology, mainly, the scheduling of resources. The scheduling optimization reflects a mixed-integer linear problem (MILP), since it involves continuous and discrete variables. In this methodology, it is not considered that the aggregator is responsible for the technical verification of the network, i.e. this is assumed to be the operator's role. Equation (1) presents the objective function implemented for the aggregator's cost minimization. The resources considered for the objective function are: the energy bought from the external suppliers $\left(P_{(s, t)}^{\text {Sup }}\right)$, the energy obtained from distributed generators $\left(P_{(p, t)}^{D G}\right)$, and the demand flexibility (reduction $-P_{(c, t)}^{\text {Red }}$, curtailment - $P_{(c, t)}^{\text {Cut }}$, shifting - $P_{(c, t, d)}^{\text {Shift }}$.

$$
\begin{aligned}
& \text { MinOC }=\sum_{s=1}^{S} P_{(s, t)}^{\text {Sup }} \cdot C_{(s, t)}^{\text {Sup }}+\sum_{p=1}^{P} P_{(p, t)}^{D G} \cdot C_{(p, t)}^{D G} \\
& +\sum_{c=1}^{C s}\left[\begin{array}{l}
P_{(c, t)}^{\text {Red }} \cdot C_{(c, t)}^{\text {Red }}+P_{(c, t)}^{\text {Cut }} \cdot C_{(c, t)}^{\text {Cut }} \\
+\sum_{d=1}^{T} P_{(c, t, d)}^{\text {Shift }} \cdot C_{(c, t, d)}^{\text {Shift }}
\end{array}\right] \\
& \forall t \in\{1, \ldots, T\}
\end{aligned}
$$

Although the aggregator does not perform the technical verification of the network, the energy balance is still required to assure that the consumers are supplied according to their consumption needs ( $\left.P_{(c, t)}^{\text {Load }}\right)$, as shown by Equation (2).

$$
\begin{aligned}
& \sum_{c=1}^{C s}\left[\begin{array}{c}
P_{(c, t)}^{\text {Load }}-P_{(c, t)}^{\text {Red }}-P_{(c, t)}^{\text {Cut }} \\
-\sum_{d=1}^{T}\left(P_{(c, t, d)}^{\text {Shift }}-P_{(c, d, t)}^{\text {Shift }}\right)
\end{array}\right] \\
& -\sum_{s=1}^{S} P_{(s, t)}^{\text {Sup }}-\sum_{p=1}^{P} P_{(p, t)}^{D G}=0 \quad \forall t \in\{1, \ldots, T\}
\end{aligned}
$$

In the following equation (3) and (4), the technical generation limits of the external suppliers $\left(P_{(s, t)}^{\text {Sup min }}, P_{(s, t)}^{\text {Sup max }}\right)$ and distributed generators $\left(P_{(p, t)}^{D G \min }, P_{(p, t)}^{D G \max }\right)$ are presented.

$$
\begin{aligned}
& P_{(s, t)}^{\text {Supmin }} \leq P_{(s, t)}^{\text {Sup }} \leq P_{(s, t)}^{\text {Sup max }} \\
& \forall s \in\{1, \ldots, S\}, \forall t \in\{1, \ldots, T\} \\
& P_{(p, t)}^{D G \min } \leq P_{(p, t)}^{D G} \leq P_{(p, t)}^{D G \max } \\
& \forall p \in\{1, \ldots, P\}, \forall t \in\{1, \ldots, T\}
\end{aligned}
$$

External suppliers and the energy amounts obtained from load shifting are not considered in neither aggregation or remuneration processes. Demand response is an important part of the proposed methodology, namely, in terms of load reduction, curtailment, and shifting. The technical limits of these programs are presented in equations (5)-(10).

$$
\begin{aligned}
& P_{(c, t)}^{\text {Red min }} \leq P_{(c, t)}^{\text {Red }} \leq P_{(c, t)}^{\text {Red max }} \\
& P_{(c, t)}^{\text {Cut min }} \leq P_{(c, t)}^{\text {Cut }} \leq P_{(c, t)}^{\text {Cut max }} \\
& P_{(c, t)}^{\text {Cut }}=P_{(c, t)}^{\text {Cut max }} \cdot X_{(c, t)}^{\text {Cut }} \\
& X_{(c, t)}^{\text {Cut }} \in\{0,1\} \\
& \forall c \in\{1, \ldots, C\}, \forall t \in\{1, \ldots, T\} \\
& P_{(c, t, d)}^{\text {Shift min }} \leq P_{(c, t, d)}^{\text {Shift }} \leq P_{(c, t, d)}^{\text {Shift max }}
\end{aligned}
$$

Equation (9) and (10) demonstrate the limitations regarding the maximum amount of energy shifted out of $\left(P_{(c, t)}^{\text {Shift_out }}\right)$, and into a given period $\left(P_{(c, t)}^{\text {Shift_in }}\right)$, respectively. Load shifting is a very useful tool for the aggregator since it allows him to better choose the periods of consumption, taking into consideration the generation available and respective price. For the consumer, this kind of approach may cause some issues taking into consideration that some appliances may be required to consume at a given time, for example, industrial processes, water heater, amongst others.

$$
\begin{aligned}
& \sum_{d=1}^{T} P_{(c, t, d)}^{\text {Shift }} \leq P_{(c, t)}^{\text {Shift_out }} \\
& \sum_{d=1}^{T} P_{(c, d, t)}^{\text {Shift }} \leq P_{(c, t)}^{\text {Shift_in }} \\
& \forall c \in\{1, \ldots, C\}, \forall t, d \in\{1, \ldots, T\}
\end{aligned}
$$

In what concerns the remuneration of resources, as mentioned before, it is considered the maximum price of the resources belonging to each group, as shown mathematically in (11). In this way, aggregation is performed considering a basis of several observations of the variables mentioned before, while remuneration is computed considering the prices applied in a given period.

$$
\begin{aligned}
& G_{(k, t)}^{D G}=\max \left(C_{(p, t)}^{D G}\right) \\
& G_{(k, t)}^{D R}=\max \left(C_{(c, t)}^{\text {Red }}, C_{(c, t)}^{C u t}\right), \forall c \in\{1, \ldots, C\} \\
& \forall p \in\{1, \ldots, P\}, \forall k \in\{1, \ldots, K\}, \forall t \in\{1, \ldots, T\}
\end{aligned}
$$

In sum, this section demonstrated the key components of the proposed methodology, regarding the scheduling and remuneration of resources managed by an aggregator. In the next section, it is detailed the case study used to validate the present methodology.

\section{CASE STUdy}

This section presents the description of the case study used to validate the proposed methodology. The considered network is composed by 21 buses, representing an university campus, as described in [15]. The network has 20 consumers 
classified by their average consumption, and 26 production generators classified by type of source. The generator's individual cost and peak production is shown in Figure 3.

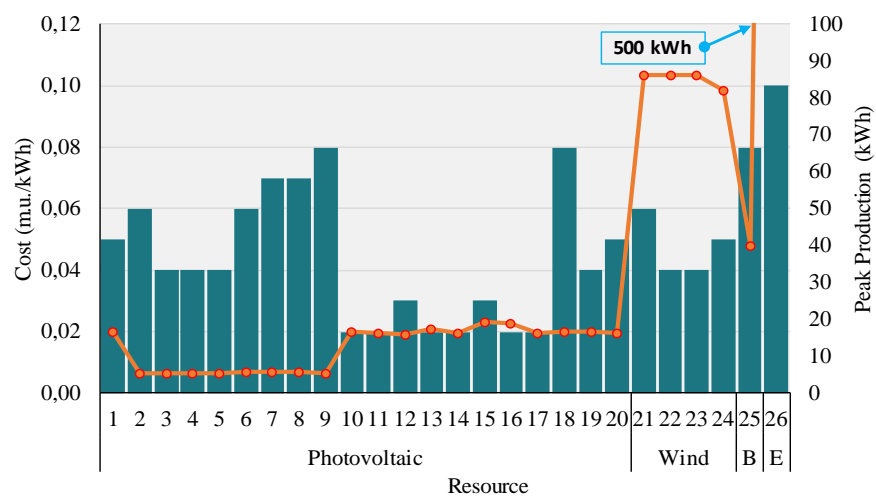

Figure 3. Generator's main features.

The energy cost of both distributed generation and external suppliers, are constant all through the periods. The bars are relative to the individual cost, while the line represents the peak production of the generators. The data shown for peak production corresponds to the maximum value expected in all periods. All producers, except for the external supplier, can participate in aggregation for energy markets. Regarding the consumers, these are divided into five types: Domestic (DM), Small Commerce (SC), Medium Commerce (MC), Large Commerce (LC), Industrial (ID). This type of assignment is performed based on their average daily consumption. In a similar way to production, Figure 4 presents the consumer's details considering their linear cost, by type of resource. The maximum reductions are $6 \%$ of the initial load for reduction, and $10 \%$ for curtailment and shifting.

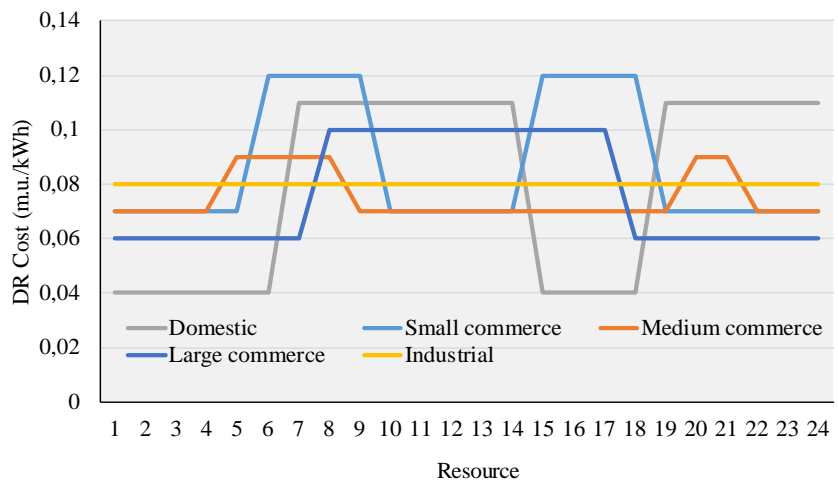

Figure 4. Linear cost for load reduction and curtailment.

In Figure 5, it is illustrated the consumption discrimination along the periods considered for the day-ahead planning. It shows that the main energy consumptions are originated from large commercial and industrial consumers. The same figure shows the periods where the distributed generation is bellow and above the consumption baseline. In these periods, the aggregator can either use the external supplier, demand-side management programs, or market sale to maintain the balance of the network. The following Figure 6 presents the considered day-ahead market prices for the aggregator to participate. To simulate the participation in the energy market by the aggregator, a market place must be considered. A market pool insures that several entities can propose energy bids, including aggregators.

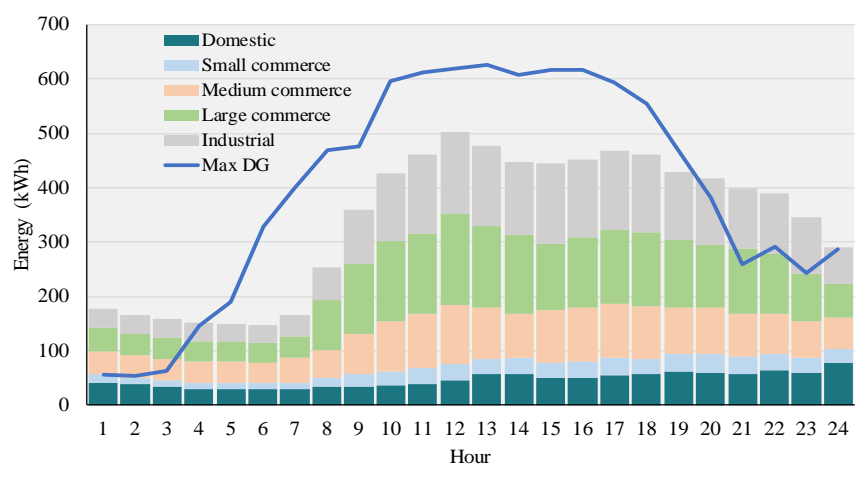

Figure 5. Day-ahead consumption expectation.

This kind of market insures competition through its participants, and therefore improve the outcome in the consumer's perspective.

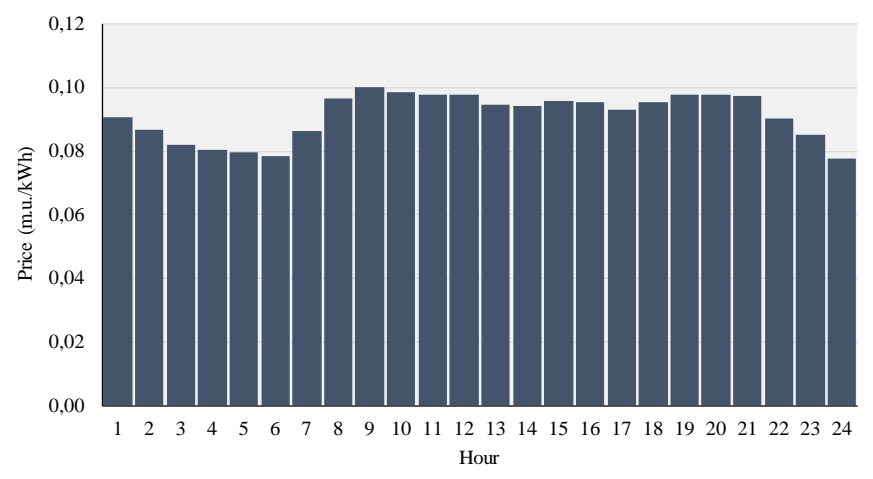

Figure 6. Energy market prices.

\section{RESULTS}

In this section, it is presented the results obtained for the scheduling, aggregation, and remuneration processes. The results concerning the market negotiation are focused, describing how the aggregator can use the results obtained to present a bid. Firstly, the scheduling results for generation are presented by Figure 7. It is considered an energy shortage from the external suppliers in the first 4 periods, being these able to support only $10 \%$ of their capacity, around $50 \mathrm{kWh}$.

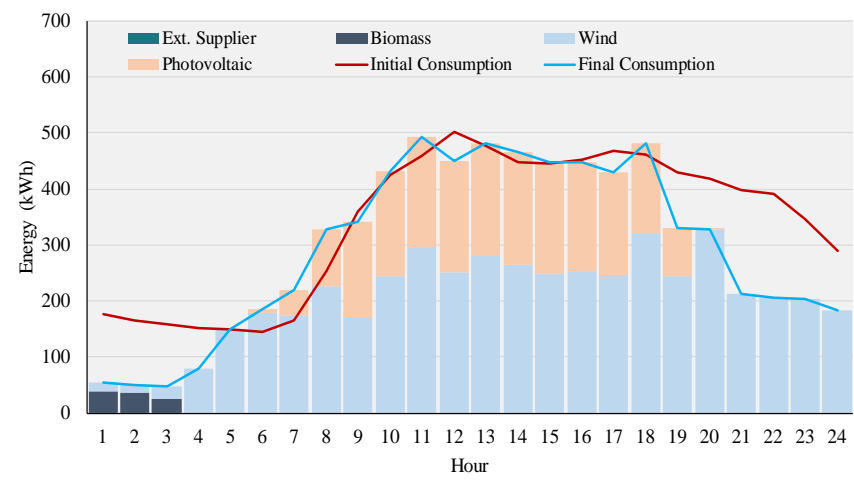

Figure 7. Generation scheduling with initial and final consumption.

This causes the aggregator to apply demand response programs that can balance the difference between production 
and expected consumption, in the periods where it is needed considering the minimization of costs. The scheduling shows a high penetration of distributed generation, expectable since the cost of it is lower than the cost of the external suppliers. The differences between initial and final consumption are related to demand response actuation, namely, load reduction, curtailment and shifting. In Figure 8, it is shown these programs implementation, where the load shifting is the difference between the initial and final consumption, aside of the light green and orange (reduction and curtailment, respectively). It is noticed that load is shifted from periods where available generation is low, to another time where generation is higher in the middle of the day.

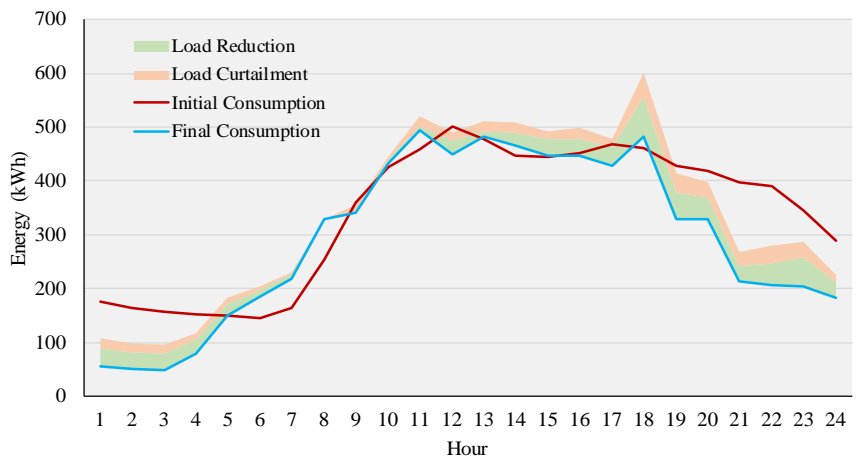

Figure 8. Demand response actuation detail, in relation with initial and final consumption.

The times where distributed generation is not sufficient, the demand-side management arises to adjust the remaining energy differences between production and consumption. Moreover, it is possible to see that during the periods of energy shortage from the distributed generators, load shifting is used to move consumption from those periods to more favorable ones, thus avoiding the buying energy from the grid, which is more expensive. Moving on to the energy market's results, in Table I, the results for the aggregation and remuneration of the resources are shown, regarding period number 12. The total energy and number of resources are outputs of the aggregation process, while the minimum bid tariff is from the remuneration process.

TABLE I. AGGREGATION AND REMUNERATION RESULTS.

\begin{tabular}{|c|c|c|c|c|c|}
\hline Bid group & 1 & 2 & 3 & 4 & 5 \\
\hline $\begin{array}{l}\text { Energy in DR groups } \\
(\mathrm{kWh})\end{array}$ & 6,09 & 9,49 & 4,04 & 17,18 & 3,55 \\
\hline Number of DR resources & 1 & 1 & 1 & 2 & 1 \\
\hline Group tariff (m.u./kWh) & 0,05 & 0,05 & 0,05 & 0,05 & 0,05 \\
\hline $\begin{array}{l}\text { Energy in DG groups } \\
(\mathrm{kWh})\end{array}$ & 30,73 & 250,58 & 16,02 & 37,72 & 114,21 \\
\hline Number of DG resources & 2 & 3 & 4 & 2 & 7 \\
\hline Group tariff (m.u./kWh) & 0,03 & 0,05 & 0,06 & 0,03 & 0,05 \\
\hline Total Energy & \multicolumn{5}{|c|}{489,62} \\
\hline
\end{tabular}

The profit after payment represents the monetary profit that the aggregator obtains from its activities, after having paid the consumers and distributed generators for their participation in the event, as defined in equation (12).

$$
\begin{aligned}
& \text { Profit }=C_{(t)}^{m c p} \cdot\left[\sum_{p \in k}^{P} P_{(p, t)}^{D G}+\sum_{c \in k}^{C}\left(P_{(c, t)}^{\text {Red }}+P_{(c, t)}^{\text {Cut }}\right)\right] \\
& -\left[G_{(k, t)}^{D G} \cdot \sum_{p \in k}^{P} P_{(p, t)}^{D G}+G_{(k, t)}^{D R} \cdot \sum_{c \in k}^{C}\left(P_{(c, t)}^{\text {Red }}+P_{(c, t)}^{C u t}\right)\right] \\
& \forall k \in\{1, \ldots, K\}, \forall t \in\{1, \ldots, T\}
\end{aligned}
$$

The accepted tariff in this case study is defined by what is presented in Figure 6, and represents as, after negotiations, the market clearing price obtained $\left(C_{(t)}^{m c p}\right)$. The consideration of several groups, allows the aggregator to obtain lower group tariffs, since if all were in the same group the highest tariff would be applied to all resources. By making several groups, there will still be a group with the highest tariff, however, there is the chance that in other groups, the group tariff is lower, and therefore less costly for the aggregator.

The results presented in Table II, show that the aggregator could profit from the distributed resources energy sell in the energy market of around 489,62 $\mathrm{kWh}$, a total of 24,10 monetary units. It is possible to conclude that a higher energy amount should be sold, the aggregator would be able to rise considerably its profits from the negotiation. It is also relevant to notice that this evaluation is for a single period, for example, a given hour of the day as the case study presented suggests. Again, the profitability of the aggregator is also dependent of the offers and capability of negotiation in the energy market by the aggregator and existing competition. The operation of the aggregator becomes an economy of scales, where with the case study presented, one shows that even with a small-size region (20 consumers and 25 distributed generators), the aggregator can profit from its market participation. By controlling a larger region or number of resources, the aggregator gains more energy capacity for clustering, and as mentioned before, market negotiation.

TABLE II. FinANCIAL BALANCE FOR THE AgGREgAtoR.

\begin{tabular}{l|c}
\hline \multicolumn{1}{c|}{ Parameter } & Value \\
\hline \hline Total costs using distributed resources (m.u.) & 24,94 \\
\hline Market clearing price (m.u./kWh) & 0,0976 \\
\hline Revenues obtained from market sell (m.u.) & 47,78 \\
\hline Profit obtained by the aggregator (m.u.) & 22,84 \\
\hline
\end{tabular}

In Figure 9, one can see the results obtained for each period regarding the participation of the aggregator in the energy market. As mentioned before, the aggregation was made considering only the resources that participated in the aggregator's scheduling in each of the periods. Each period's aggregation therefore, considers the characteristics and scheduling of the resources in that time.

Further on, a comparison is made regarding the influence of load shifting in the costs. The comparison is made between 
the total costs of the aggregator in the current scenario (WS), and in one when instead of load shifting availability, there is enough energy available from the external suppliers (WOS).

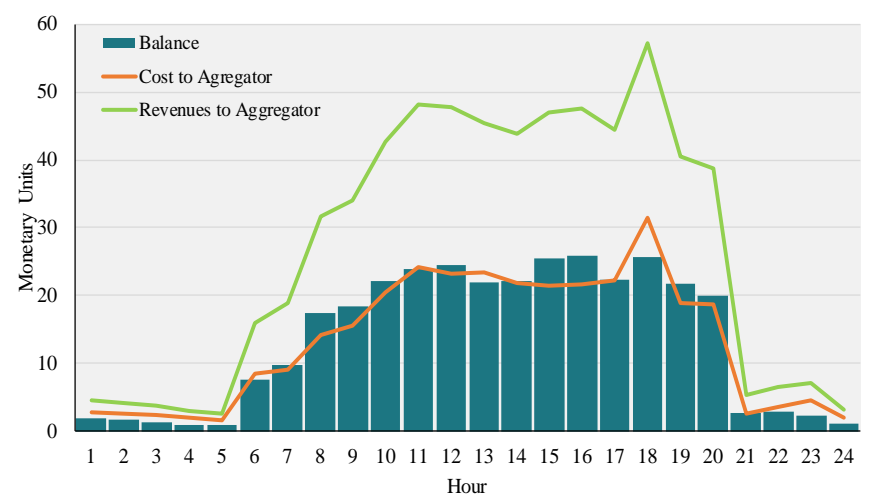

Figure 9. Profit from operating in each period.

In Table III, the results of the scenarios comparison show that the influence of load shifting availability affects considerably the total costs of the aggregator, since these are mostly balanced by the contributions that distributed generators and external suppliers provide for the scheduling. In scenario without load shifting, in the first four periods, the generation from external suppliers is raised in $50 \mathrm{kWh}$, obtaining a total of $100 \mathrm{kWh}$. This is performed so that energy balance can be obtained without load shifting.

TABLE III. WS AND WOS COMPARISON

\begin{tabular}{c|l|c|c}
\hline \hline \multicolumn{1}{c|}{ Scenario } & Value & Total \\
\hline \hline \multirow{2}{*}{ WS } & Total costs using distributed resources (m.u.) & 286,41 & \multirow{2}{*}{286,41} \\
\cline { 2 - 4 } & Total costs using external suppliers (m.u.) & 0 & \\
\hline \multirow{2}{*}{ WOS } & Total costs using distributed resources (m.u.) & 279,87 & \multirow{2}{*}{300,27} \\
\cline { 2 - 4 } & Total costs using external suppliers (m.u.) & 20,40 & \\
\hline
\end{tabular}

\section{CONCLUSIONS}

The current paper addresses an aggregator's methodology for the management of distributed energy resources, namely, distributed generation and demand-side flexibility. The focus is given to the energy market negotiation process performed by the aggregator, which upon ensures the introduction of small-size resources into energy markets, while provides a business model for profitability of operation.

Results show that the aggregator can perform the scheduling regarding the distributed energy resources contribution, implementing different types of operation programs, mainly, in the through demand-side resources. In this way, the aggregator can obtain the network balance and the participation of each resource. Aggregation and remuneration results show that the methods used, affect the outcome of profit for the aggregator, and thus further study and development is needed. However, the aggregator by using this methodology can obtain the operation balance and a fair usage of distributed energy resources for its activities.

\section{REFERENCES}

[1] S. M. Nosratabadi, R.-A. Hooshmand, and E. Gholipour, "A comprehensive review on microgrid and virtual power plant concepts employed for distributed energy resources scheduling in power systems,” Renew. Sustain. Energy Rev., vol. 67, pp. 341-363, 2017.

[2] C. Battistelli and A. J. Conejo, "Optimal management of the automatic generation control service in smart user grids including electric vehicles and distributed resources,” Electr. Power Syst. Res., vol. 111, pp. 22-31, 2014.

[3] A. Roos, S. Ø. Ottesen, and T. F. Bolkesjø, "Modeling Consumer Flexibility of an Aggregator Participating in the Wholesale Power Market and the Regulation Capacity Market," Energy Procedia, vol. 58, pp. 79-86, 2014.

[4] D. J. Vergados, I. Mamounakis, P. Makris, and E. Varvarigos, "Prosumer clustering into virtual microgrids for cost reduction in renewable energy trading markets,” Sustain. Energy, Grids Networks, vol. 7, pp. 90-103, 2016.

[5] S. Rahnama, S. E. Shafiei, J. Stoustrup, H. Rasmussen, and J. Bendtsen, "Evaluation of Aggregators for Integration of Large-scale Consumers in Smart Grid,” IFAC Proc. Vol., vol. 47, no. 3, pp. 18791885, 2014.

[6] EG3 Report - Smart Grid Task Force, "Regulatory Recommendations for the Deployment of Flexibility,” 2015.

[7] Smart Energy Demand Coalition, "Mapping Demand Response in Europe Today 2015,” 2015.

[8] Smart Energy Demand Coalition, "Enabling independent aggregation in the European electricity markets,” 2015.

[9] Smart Grid Task Force, "Regulatory Recommendations for the Deployment of Flexibility,” 2015.

[10] Federal Energy Regulatory Commission, "Assessment of Demand Response \& Advanced Metering,” 2011.

[11] S. Rahmani-Dabbagh and M. K. Sheikh-El-Eslami, "A profit sharing scheme for distributed energy resources integrated into a virtual power plant,” Appl. Energy, vol. 184, pp. 313-328, 2016.

[12] P. Faria, J. Spínola, and Z. Vale, "Aggregation and Remuneration of Electricity Consumers and Producers for the Definition of\&\#x00A0;Demand-Response Programs," IEEE Transactions on Industrial Informatics, vol. 12, no. 3. pp. 952-961, 2016.

[13] N. Mahmoudi, E. Heydarian-Forushani, M. Shafie-khah, T. K. Saha, M. E. H. Golshan, and P. Siano, "A bottom-up approach for demand response aggregators' participation in electricity markets," Electr. Power Syst. Res., vol. 143, pp. 121-129, 2017.

[14] P. Faria, Z. Vale, and J. Baptista, "Constrained consumption shifting management in the distributed energy resources scheduling considering demand response," Energy Convers. Manag., vol. 93, pp. 309-320, 2015.

[15] M. Silva, F. Fernandes, H. Morais, S. Ramos, and Z. Vale, "Hourahead energy resource management in university campus microgrid," PowerTech, 2015 IEEE Eindhoven. pp. 1-6, 2015. 